\title{
EL PATRONATO DE MISIONES PEDAGÓGICAS, EL FRENTE DE JUVENTUDES Y LA SECCIÓN FEMENINA: INSTITUCIONES CLAVE EN LA HISTORIA DE LA EDUCACIÓN MUSICAL EN LA ENSEÑANZA PRIMARIA ESPAÑOLA
}

\section{The Patronato de Misiones Pedagógicas, the Frente de Juventudes and the Sección Femenina: key institutions in the bistory of Spanish music education in primary schools}

Narciso José López García

Departamento de Didáctica de la Expresión Musical-Grupo LabinTic. Facultad de Educación de Albacete-Universidad de Castilla-La Mancha

Correo-e: njlopezg@gmail.com; narcisojose.lopez@uclm.es

María del Valle De Moya MarTínez

Departamento de Didáctica de la Expresión Musical-Grupo LabinTic. Facultad de Educación de Albacete-Universidad de Castilla-La Mancha

Correo-e: mariavallede.moya@uclm.es

Recepción: 27 de mayo de 2016

Envío a informantes: 23 de julio de 2016

Aceptación definitiva: 27 de abril de 2017

Resumen: La educación musical en España quedaba regulada y estructurada a finales del siglo Xx con la LOGSE (I990) aunque, anteriormente, hubo diversos intentos por iniciar una musicalización educativa entre niños y jóvenes. En las páginas que siguen mostramos una breve, pero aclaradora, contextualización en base a la legislación educativo-musical producida durante el siglo xx centrada, fundamentalmente, en la escuela primaria española, siendo el objetivo principal del presente artículo destacar las actuaciones de culturización y enseñanza musical llevadas a cabo durante los dos primeros tercios del pasado siglo, poniendo de relieve la gran innovación que, incluso a nivel europeo, supuso la actuación, por un lado, del Patronato de Misiones Pedagógicas, impulsado por la II República española bajo el ideario de la Institución Libre de Enseñanza, 
y, por otro lado, de la Sección Femenina, destacando el papel jugado por las llamadas Cátedras Ambulantes y Cátedras José Antonio y la del Frente de Juventudes, ambas organizaciones auspiciadas por la dictadura franquista.

El método de investigación empleado ha sido el análisis de información, manteniendo la objetividad y la precisión en las interpretaciones presentadas.

Palabras clave: educación musical; Misiones Pedagógicas; Frente de Juventudes; Sección Femenina; cátedras ambulantes.

Aвstract: Music education in Spain was regulated and structured in the late twentieth century by means of the Educational Act LOGSE (1990) although, previously, there were several attempts to start an educational musicality among children and youth. In the following pages we show a brief but clarifying, context of educational legislation about music education produced during the twentieth century focused primarily on the Spanish primary education.

The main objective of this article is to highlight the performances of acculturation and music education carried out during the first third of the last century. For that, we want to emphasize the great innovation that even on a European level was carried out, on the one hand, by the Patronato de Misiones Pedagógicas, driven by the second Spanish Republic, under the ideology of Free Institution of Education and on the other hand, by the Sección Femenina, with a decisive role played by both itinerant chairs and the professorships Jose Antonio and the Frente de Juventudes, sponsored by the Franco dictatorship.

We used as a research method the analysis of information, maintaining objectivity and accuracy in our interpretations showed.

KEY wORDs: music education; educational missions; Frente de Juventudes; Sección Femenina; itinerant chairs.

\section{Introducción}

$\tau$

a entrada en vigor de la Ley Orgánica i/I990, de 3 de octubre de i990, de Ordenación General del Sistema Educativo (LOGSE) supuso, entre otros asuntos, la incorporación obligatoria de la Educación Musical en los currículos oficiales de las enseñanzas obligatorias de nuestro país. Hasta ese momento, la enseñanza de la música en la historia de la educación española había pasado por diferentes etapas, todas ellas con un denominador común: la carencia de unas instrucciones y de un desarrollo curricular precisos y estructurados.

Sin embargo, cabe destacar dos períodos concretos en los que la Educación Musical formó parte de diversos programas llevados a cabo con la intención de acercar la cultura a las zonas más deprimidas del país y a las personas con menos recursos y, por tanto, con mayores necesidades educativas. Estas etapas, que coinciden en el tiempo con la proclamación y puesta en marcha de la II República española (I93I-I939), por un lado, y con la dictadura franquista (1939-I975), por otro, contaron con tres instituciones que se encargaron de realizar esa labor: el Patronato de Misiones Pedagógicas, el Frente de Juventudes y la Sección Femenina.

Es sobradamente conocida la filiación ideológica de cada una de estas organizaciones y de los gobiernos con las que nacieron, así como el objetivo último de sus planes de acción. Pero nuestro interés no se centra en este aspecto, analizado 
EL PATRONATO DE MISIONES PEDAGÓGICAS, EL FRENTE DE JUVENTUDES

Y LA SECCIÓN FEMENINA: INSTITUCIONES CLAVE EN LA HISTORIA...

NARCISO JOSÉ LÓPEZ GARCÍA Y MARÍA DEL VALLE DE MOYA MARTÍNEZ

y desarrollado en profundidad en numerosas publicaciones y por un buen número de expertos, sino en la influencia y en la aportación de éstas en la evolución de la Educación Musical en España.

Para ello, nos ha parecido fundamental tener un punto de referencia que marque las pautas de nuestra investigación, por lo que hemos creído conveniente realizar una visión panorámica por la situación de la enseñanza de la música desde los comienzos del siglo XIX, momento en el que surgen los primeros métodos educativos nacionales, hasta la puesta en marcha de la LOGSE, con la introducción de la Educación Musical en las enseñanzas obligatorias y de la figura del docente Especialista de Música como encargado de su magisterio.

Desde esta perspectiva, queremos comenzar haciendo nuestras las palabras de López Casanova (2002a), que resume la situación de la enseñanza de la música en las políticas educativas del siglo XIX señalando que los distintos documentos legales que surgieron en este período se centraron, fundamentalmente, en la escolarización y la alfabetización del pueblo, por lo que se apostó por el afianzamiento de las materias instrumentales, de ahí que las referencias explícitas a la Educación Musical sean prácticamente nulas. Aun así, tenemos constancia de que en algunas escuelas sí existía la asignatura de música, seguramente debido a iniciativas personales de maestros o de miembros de las juntas locales y municipales de algunos ayuntamientos, al igual que en centros privados y a través de clases particulares, aunque más como una disciplina de adorno que como una materia fundamental.

Con respecto a la Educación Musical en el siglo xx, Díaz Gómez y Giráldez (2007) no dudan en afirmar que, en el caso de España, el último período ha sido, probablemente, el más productivo en este campo. Aun así, los vaivenes en política educativa producidos en la primera mitad de siglo hicieron que la música apareciera y desapareciera de los currículos, generando una sensación de desconcierto entre el profesorado, que se agravaría por la falta de formación docente para poder impartirla. Además, la música no pasó de ser una materia de descanso o un «arma disciplinaria» para controlar las entradas, las salidas y los cambios de clase del alumnado, evitando que se produjeran momentos de alboroto (López Casanova, 2002a).

Longueira (20II) nos recuerda que el proceso de graduación de la escuela (se inicia en I898 y se extenderá hasta bien entrados los años 70), en el que la Educación Musical aparecía como materia a impartir en las escuelas de prácticas anejas a las Normales, impulsó los procesos de enseñanza y aprendizaje de la música, pero sólo en aquellos centros destinados a esa misión. En esta misma línea se aprobaba el Real Decreto de 26 de octubre de Igor sobre la Reforma de la Enseñanza Primaria, que incluía el Canto como una de sus materias para los tres grados en que quedaba dividida la escuela pública, distinguiéndose únicamente por la amplitud de programa y por el carácter pedagógico y duración de sus ejercicios (López García, 20I5).

Paralelamente, el nacimiento de la JAE (Junta para la Ampliación de Estudios e Investigaciones Científicas), en 1907 , favoreció el contacto de varios becados con las corrientes pedagógicas europeas que, a su vuelta, se encargaron de divulgar los conocimientos adquiridos en publicaciones de la época como la Revista de Pedagogía (1922-1936) o el Boletín de la Institución Libre de Enseñanza (r. ${ }^{a}$ etapa: entre I877 y 1936-2. ${ }^{a}$ etapa: fin de la Guerra Civil-1987). En estos artículos se consideraba la necesidad de adquirir una cultura musical en la escuela distinta a los planteamientos que hasta entonces se tenían, dirigidos, especialmente, a la producción de músicos 
EL PATRONATO DE MISIONES PEDAGÓGICAS, EL FRENTE DE JUVENTUDES

Y LA SECCIÓN FEMENINA: INSTITUCIONES CLAVE EN LA HISTORIA...

NARCISO JOSÉ LÓPEZ GARCÍA Y MARÍA DEL VALLE DE MOYA MARTÍNEZ

profesionales. Sin embargo, Romero Carmona (2005) nos vuelve a recordar que la Educación Musical no fue recogida en los planes de estudios de la época ni se incluyó oficialmente en el currículo.

Entre 1930 y 1936, los becados de la JAE, influenciados por los movimientos pedagógicos cercanos a la Escuela Nueva, impulsaron una enseñanza de la música diferente que quedaría reflejada en el Decreto de 28 de octubre de 1937, fijando el plan de estudios que ha de regir en la Escuela Primaria Española, así como en la Orden de II de noviembre de 1937, dando instrucciones para la aplicación del plan de estudios y distribución semanal del tiempo en la Escuela Primaria de conformidad con las instrucciones y formularios que se inserta. Desafortunadamente, la Guerra Civil y el posterior período de dictadura en el que se sumió el país acabaron con cualquier intento de renovación pedagógica, dando paso a un fuerte intervencionismo educativo en el que la Educación Musical sufrió un acusado abandono en la práctica diaria y se centró, fundamentalmente, en la enseñanza de cantos patrióticos y religiosos (López García, 20I5). Sobre este mismo asunto, Castañón (2009) alude a los contenidos musicales con tintes claramente políticos más que educativos, por lo que la materia se fue convirtiendo, poco a poco, en una actividad indefinida, similar a otras actividades de ocio que se impartiría en un ámbito extraescolar teñido de mensajes ideológicos.

No será hasta 1965 cuando se comience a observar cierto aperturismo en materia educativa que, en el ámbito de la Educación Musical, se verá reflejado en la programación y celebración de cursos de especialización durante varios años, impartidos por Carl Orff y por Joss Wuytack, y en la concesión de becas para asistir a cursos en el extranjero sobre Metodologías Activas y Métodos Instrumentales'.

Estas dos actuaciones serán el germen de los contenidos musicales que recogerá la Ley General de Educación de 1970 (Reyes, 2005) que, si bien suponían un avance espectacular, quedaban muy alejados de la realidad europea en la que las nuevas corrientes pedagógico-musicales, basadas en el desarrollo de la creatividad y en la introducción de la música contemporánea en el aula, se consolidaban como propuestas dominantes (Díaz Gómez y Giráldez, 2007). Además, algunos profesionales de la Educación Musical como Oriol (2005), Lorenzo Quiles (2003), Morales (2008) y Romero Carmona (2005), entre otros, coinciden en señalar que las buenas intenciones plasmadas en esta Ley no fueron más allá del plano teórico.

Las normas educativas surgidas en los primeros años de democracia tras la aprobación de la Constitución de 1978 (LOECE y LODE) reducirán la enseñanza de la música a actividades puntuales y fortuitas, pero sin olvidar el camino recorrido hasta el momento, punto de partida en la configuración de la Ley Orgánica ı/ı99o, de 3 de octubre de 1990, de Ordenación General del Sistema Educativo (LOGSE).

La LOGSE introdujo grandes modificaciones estructurales y curriculares en nuestro sistema educativo y supuso un cambio radical con respecto a las leyes anteriores (Romero, 20II).

Con esta Ley, la Educación Musical pasaba a ser una disciplina reglada y obligatoria, con un desarrollo curricular específico, un horario establecido y de cuyo magisterio

Violeta Hemsy de Gainza (2003) llama Metodologías Activas a aquellas que surgen entre 1940 y 1950 en el campo de la educación musical, al amparo de la Escuela Nueva. Las figuras más representativas de este movimiento son Émile Jaques-Dalcroze, Maurice Martenot y Edgar Willems. Con el término Métodos Instrumentales se refiere a las pedagogías surgidas entre 1950 y 1970 de las que sus máximos exponentes son Zoltán Kodály y Carl Orff. 
EL PATRONATO DE MISIONES PEDAGÓGICAS, EL FRENTE DE JUVENTUDES

Y LA SECCIÓN FEMENINA: INSTITUCIONES CLAVE EN LA HISTORIA...

NARCISO JOSÉ LÓPEZ GARCÍA Y MARÍA DEL VALLE DE MOYA MARTÍNEZ

se haría cargo, obligatoriamente, un maestro con la especialización correspondiente (López García, 2015).

Las tres Leyes Educativas posteriores a la LOGSE (LOCE, LOE y LOMCE) han pasado por alto las propuestas de mejora realizadas por los profesionales de la Educación Musical surgidas de la puesta en práctica de los currículos desarrollados en la LOGSE, incluso han mermado la carga lectiva de esta materia, especialmente en la etapa de Educación Secundaria Obligatoria. De hecho, la Ley de Educación vigente, Ley Orgánica 8/2013, de 9 de diciembre, para la mejora de la calidad educativa (LOMCE), ha eliminado esta materia del grupo de asignaturas obligatorias (troncales), colocándola dentro de las asignaturas específicas cuya oferta dependerá de las administraciones educativas y, en su caso, de la oferta de los propios centros docentes, desoyendo las recomendaciones tanto de los diferentes colectivos españoles relacionados con la Educación Musical como de la Unión Europea sobre la importancia de incluir en los currículos de los sistemas educativos nacionales las enseñanzas artísticas desde las edades más tempranas.

\section{Método de trabajo}

Nuestro trabajo se ha fundamentado en el denominado análisis de información, entendido éste como la forma de investigar cuyo objetivo principal consiste en captar, evaluar, seleccionar y sintetizar los mensajes contenidos en una serie de documentos (Dulzaides y Molina, 2004). Esta estrategia metodológica está íntimamente relacionada con el análisis de contenido y el análisis documental, en los que la descripción y la interpretación de la información y de las ideas contenidas en los textos sometidos a estudio se han configurado como eje principal de nuestra investigación desde un enfoque sistemático y objetivo (Bardin, 2002).

\section{El papel del Patronato de Misiones Pedagógicas, el Frente de Juventudes y la Sección Femenina en la historia de la Educación Musical en España}

Una vez contextualizada nuestra investigación, nos centraremos en el objetivo principal de la misma: conocer el grado de influencia de estas tres instituciones en la evolución de la enseñanza de la música en la educación básica de nuestro país.

Para ello, hemos realizado un importante proceso de búsqueda y vaciado de bibliografía, comprobando la carga ideológica que ha perseguido, persigue y, desafortunadamente, perseguirá a las tres instituciones. Desde nuestro punto de vista, esto ha generado una extraña animadversión hacia las mismas desde posicionamientos sociopolíticos muy dispares, cuyas consecuencias han sido nefastas a la hora de valorar el papel de éstas como agentes impulsores de la educación y la cultura musicales en España.

Somos conocedores, por tanto, de la existencia de diferentes sensibilidades relacionadas con el tema que nos ocupa, así como del fuerte vínculo de la cultura artística con la ideología en ambos períodos (Pérez Zalduondo, 2006), por lo que hemos querido alejarnos de confrontaciones ajenas a nuestros objetivos, centrando nuestra labor en recoger, estudiar y analizar todas aquellas acciones realizadas por estas organizaciones 
EL PATRONATO DE MISIONES PEDAGÓGICAS, EL FRENTE DE JUVENTUDES

Y LA SECCIÓN FEMENINA: INSTITUCIONES CLAVE EN LA HISTORIA...

NARCISO JOSÉ LÓPEZ GARCÍA Y MARÍA DEL VALLE DE MOYA MARTÍNEZ

que han tenido relación con la Educación Musical, con el fin último de aportar conocimiento sobre la evolución de la enseñanza de la música en la escuela española.

\section{El Patronato de Misiones Pedagógicas}

Las primeras referencias de que disponemos relacionadas con las Misiones Pedagógicas se remontan a i88I, cuando Giner de los Ríos y Cossío solicitaron al ministro de Fomento de la época la creación de misiones ambulantes con las que llevar maestros debidamente cualificados a las aldeas más apartadas. Pero no será hasta el año 1907 cuando el Real Decreto de io de enero establezca la creación de una Junta para el fomento de la educación nacional, que se hará cargo de organizar y dirigir las instituciones complementarias de la escuela, las clases de adultos, las misiones y conferencias pedagógicas, las bibliotecas populares y circulantes, colonias y cantinas escolares. Sin embargo, la precaria situación económica del país, las necesidades urgentes de la enseñanza (pago y mejora de sueldos de los maestros, restauración de edificios escolares ruinosos, escaso material escolar, deficiente mobiliario...) y los continuos cambios políticos y, como consecuencia de ello, las constantes modificaciones legislativas, que en lugar de ofrecer soluciones creaban una gran confusión administrativa, fueron las principales causas de la escasa repercusión de estas misiones durante cerca de treinta años (Canes, 1993).

Habrá que esperar hasta el año I93I, con la proclamación de la Segunda República española (I4 de abril de I93I) cuando, por Decreto de 29 de mayo, se cree el Patronato de Misiones Pedagógicas, bajo la presidencia de Manuel Bartolomé Cossío (Martín, 2002) y con el apoyo de las personas más cercanas a la órbita de la ILE, con el fin de difundir la cultura general, la actualización docente y la educación ciudadana en las zonas rurales, desde la idea de tender puentes de unión entre el mundo rural y el mundo urbano. Este paso ponía de manifiesto la preocupación del Gobierno republicano por la educación del pueblo, inquietud que culminaría con la construcción de un verdadero sistema educativo nacional acorde a estos nuevos tiempos (De Puelles, 1991).

Desde esta perspectiva, se ponían en marcha una serie de actividades en las que se incluían audiciones de música coral, formación de pequeñas orquestas, audiciones radiofónicas o audiciones de discos seleccionados. De esta forma, el Patronato apostaba por impulsar, de manera significativa, el valor de la Educación Musical como parte fundamental de su idea de potenciar la educación ciudadana, por lo que se realizó un claro esfuerzo por llevar la cultura musical a toda la población (Ocaña, 2006).

El origen de su creación, según el propio Cossío, hay que buscarlo en la diferencia abismal, no sólo intelectual, también económica, existente entre el campo y la ciudad. Con las Misiones se pretendió llevar a los aldeanos, niños y adultos, parte de aquello que poseían los habitantes de las ciudades, puesto que tenían el mismo derecho a disfrutar de la cultura (Canes, 1993).

Una definición clara sobre el papel del Patronato la encontramos en el documental Las Misiones Pedagógicas (Tapia, 2006), donde, en una de las proyecciones recuperadas para esta investigación audiovisual, se proclama:

Somos una escuela ambulante que quiere ir de pueblo en pueblo. A los más pobres, a los más escondidos, a los más abandonados... A estos pueblos, a estas gentes, se dirige la Misión. Lleva proyectores, gramófonos, libros. Su camioneta corre a campo traviesa y cruza ríos. 
EL PATRONATO DE MISIONES PEDAGÓGICAS, EL FRENTE DE JUVENTUDES

Y LA SECCIÓN FEMENINA: INSTITUCIONES CLAVE EN LA HISTORIA...

NARCISO JOSÉ LÓPEZ GARCÍA Y MARÍA DEL VALLE DE MOYA MARTÍNEZ

El programa de actividades culturales incluía carteles anunciadores de los actos y el transporte del material necesario para poner en práctica la misión, quedando ésta estructurada, generalmente, del siguiente modo:

- Biblioteca fija y circulante.

- Cine y proyecciones fijas.

- Museo circulante.

- Coro y teatro del pueblo.

- El retablo de fantoches (guiñol).

- Cursos para maestros.

- Servicio de música.

El Coro y el Servicio de música eran las dos actividades propiamente musicales que se incluían en el programa de las Misiones.

El Coro estaba integrado por unos cincuenta estudiantes dirigidos por Eduardo Martínez Torner y su repertorio estaba compuesto por canciones recogidas del folclore, romances, cantigas y serranillas que los espectadores reconocían con facilidad. Generalmente, las canciones populares y los recitados se interpretaban en los intermedios de las escenificaciones aunque, en ocasiones, la música y el canto se integraban dentro de las propias representaciones teatrales.

Algunos de los romances y canciones populares que integraron el repertorio del Coro fueron: El pañuelo a la moda (giraldilla asturiana), Al monte voy por rama (León), En Samir de los Caños (Zamora), Las estrellas corren, corren (canción de ronda de Salamanca y Segovia), El Conde Olinos, Más vale trocar (Juan del Encina),

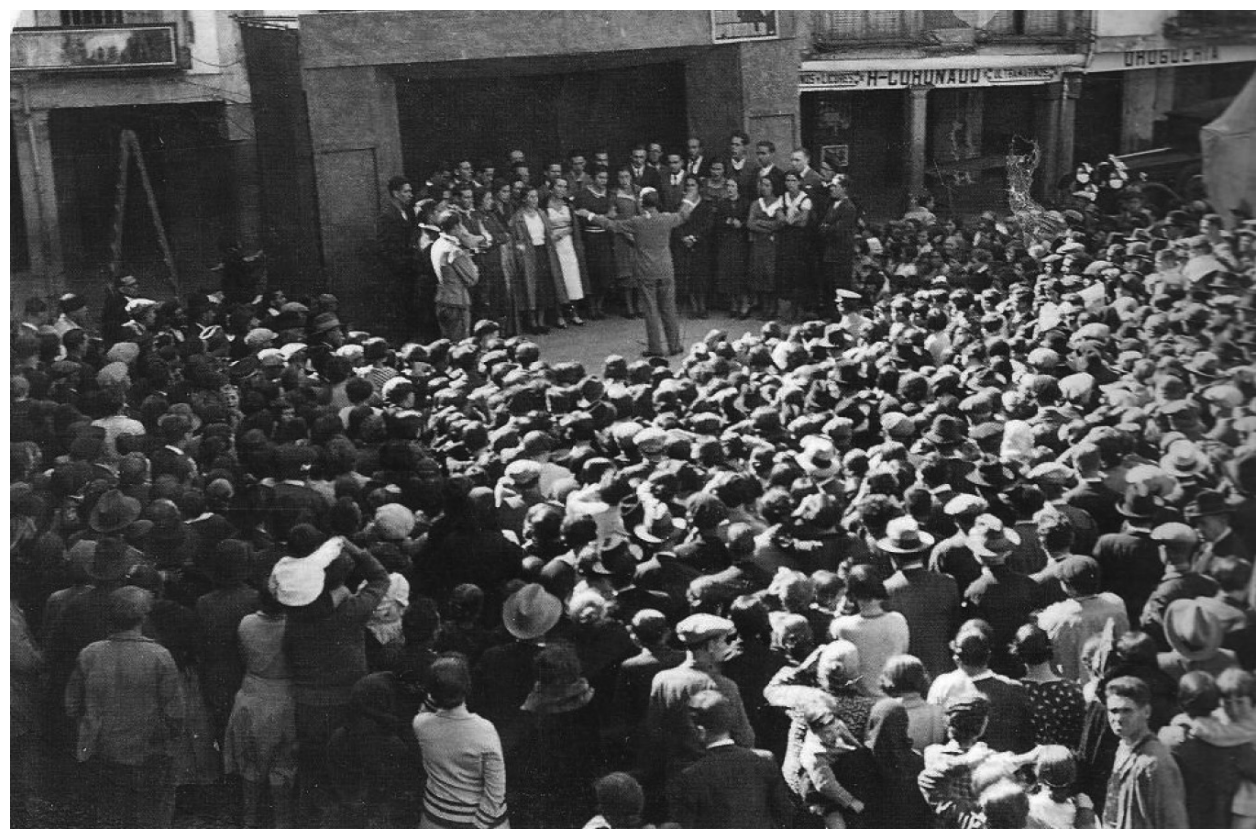

Figura i. Coro de las Misiones Pedagógicas dirigido por Martínez Torner (en http://conservatoriodelnalon.com/category/cursos-y-talleres/). 
Romance del Conde Sol, La loba parda, El pastor desesperado, La Condesita y Misa de amor (SECC, 2007).

La Memoria del Patronato publicada en 1934 especifica que el radio de acción del Coro fue reducido, limitándose a los alrededores de Madrid. Hasta el día 30 de diciembre de I933, se visitaron IIs pueblos pertenecientes a las provincias de Madrid, Ávila, Segovia, Toledo, Cuenca, Ciudad Real y Guadalajara. La primera actuación se llevó a cabo en Esquivias (Toledo), el día Is de mayo de 1932 (en Canes, I993: I58).

El Servicio de música estuvo constituido por la cesión de un gramófono y una colección de discos de repertorio popular y clásico a algunas localidades. Este material se utilizaba tanto para la labor escolar como para la educación de adultos. Los maestros se encargarían de poner música a los niños a la entrada y a la salida de la escuela, en horario de clase y en los recreos (López Casanova, 2002b).

Eduardo Martínez Torner, Óscar Esplá y Pablo de Andrés se encargaron de seleccionar el material musical, de diseñar los programas y de enseñar un buen número de canciones populares a los misioneros y componentes del Coro.

El objetivo del Servicio de música consistió en difundir cultura a través de audiciones de música coral, de pequeñas orquestas y de audiciones de discos y obras seleccionadas que se explicaban y se comentaban.

La persona responsable de la custodia y buen uso del material musical, normalmente el maestro del pueblo, se encargaría de renovar periódicamente las colecciones de discos y de desplazarse a otras poblaciones cercanas para realizar sesiones musicales con los niños y adultos de esos lugares (López García, 2015).

Las colecciones de discos comprendían obras de canto gregoriano, lírica regional española, zarzuela y una selección de obras de compositores españoles como Bretón,

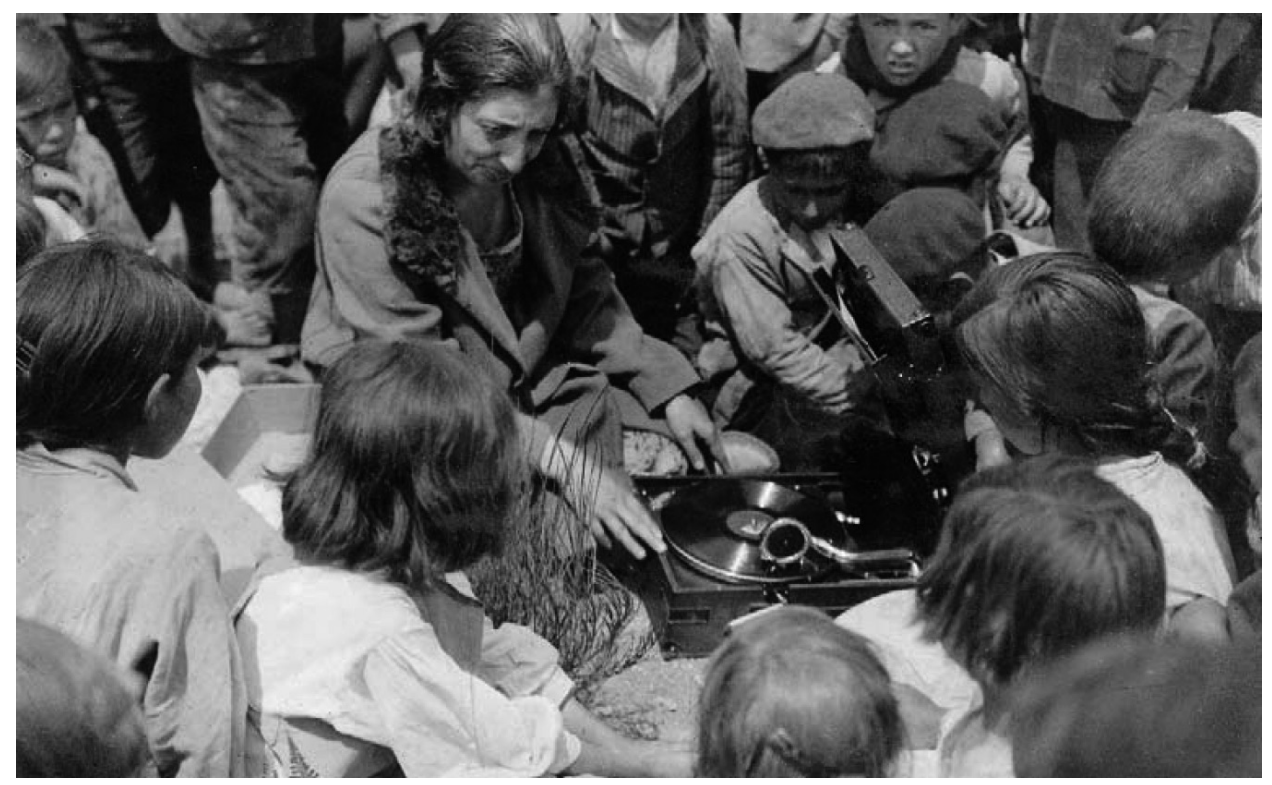

Figura 2. Audición musical programada por el Servicio de música (1932) [en Catálogo de la exposición Las misiones pedagógicas 193I-1936 (SECC-2006, p. 2I)]. 
EL PATRONATO DE MISIONES PEDAGÓGICAS, EL FRENTE DE JUVENTUDES

Y LA SECCIÓN FEMENINA: INSTITUCIONES CLAVE EN LA HISTORIA...

NARCISO JOSÉ LÓPEZ GARCÍA Y MARÍA DEL VALLE DE MOYA MARTÍNEZ

Chapí, Falla, Albéniz, Esplá o Turina, y de compositores extranjeros como Bach, Haendel, Beethoven, Mozart, Mendelssohn, Schubert, Strauss, Brahms, Debussy, Saint Saëns, Borodin, Mussorgski, Rimsky Korsakoff, Grieg, Dukas, Puccini, Ravel o Stravinski.

A finales de 1933 se habían repartido 38 gramófonos con sus respectivas colecciones de discos, quedando confiados, en su mayoría, a los maestros nacionales (Canes, 1993).

Conrad Vilanou (en Romero Carmona, 2009: 32) expone que las Misiones Pedagógicas se encargarían de potenciar, junto a su lucha contra el analfabetismo, las manifestaciones artísticas (música, cine, teatro y pintura). Su fórmula letras y arte simbolizaría la búsqueda de unos valores espirituales apoyados en la riqueza material que tenían a su alcance para llevar su labor por toda España.

El segundo bienio del Gobierno republicano (1933-1935) se caracterizó por la puesta en marcha de distintas contrarreformas legislativas que cercenaron, en cierta medida, los avances conseguidos en el terreno educativo. Las Misiones Pedagógicas también se vieron afectadas, principalmente, por la falta de comprensión hacia la función que desempeñaban y así, en I935, se redujo su asignación presupuestaria y, como consecuencia más directa, su actividad.

La Guerra Civil (1936-1939) terminó definitivamente con su tarea pedagógica. En el recuerdo quedan su filosofía, su trabajo, sus éxitos y, sobre todo, el hecho de haber sido una de las experiencias culturales más innovadoras y originales emprendidas por un Gobierno europeo en todo el siglo xx (SECC, 2007).

\section{El Frente de Juventudes y la Sección Femenina: las dos instituciones políticas del Movimiento con competencias en Educación Musical}

El Frente de Juventudes y la Sección Femenina son las dos instituciones que nacen en el marco de la Falange y al amparo del Movimiento Nacional, y cuyo objetivo fundamental será el de fomentar y difundir las ideas tradicionalistas y religiosas del régimen mediante un complejo entramado organizativo y burocrático centrado, principalmente, en la formación de las masas, según los dictámenes marcados por el propio Movimiento, de forma paralela al sistema educativo nacional.

Aunque, como nos recuerdan Manrique, López, Torrego y Mongas (2008), la Sección Femenina estuvo integrada dentro del Frente de Juventudes conforme se indicaba en la Ley de 6 de diciembre de 1940, pronto surgirían grandes divergencias, especialmente metodológicas, haciendo necesaria la publicación de la Orden de 24 de enero de 1945, por la que quedaban configuradas como instituciones independientes.

Su campo de acción estuvo delimitado a la formación de la población masculina, en el caso del Frente de Juventudes, y a la formación de la femenina, en el caso de la Sección Femenina. Con esta distinción, se hacían efectivas la Orden de 2 I de septiembre de 1936, la Circular de s de marzo de 1938 y el Decreto de 4 de septiembre de 1938, por lo que se prohibía la coeducación en la enseñanza española (Sánchez Blanco, 20I2), normativa que se mantendría vigente hasta 1970, con la publicación de la Ley General de Educación (LGE).

El Frente de Juventudes se crea en 1940 con la finalidad de adoctrinar física y políticamente a la juventud de acuerdo con los principios del régimen (Cañabate, 2003-2004). La formación llevada a cabo por éste tendrá un marcado carácter político 
EL PATRONATO DE MISIONES PEDAGÓGICAS, EL FRENTE DE JUVENTUDES

Y LA SECCIÓN FEMENINA: INSTITUCIONES CLAVE EN LA HISTORIA...

NARCISO JOSÉ LÓPEZ GARCÍA Y MARÍA DEL VALLE DE MOYA MARTÍNEZ

y premilitar y se desarrollará, sustancialmente, en el ámbito extraescolar y no formal mediante la organización de campamentos, excursiones, desfiles y actividades de ocio de todo tipo. En los años 60 pasará a denominarse oJE (Organización Juvenil Española), nomenclatura que perdurará hasta 1977, año de su disolución.

Por su parte, la Sección Femenina se crea en 1934, siendo en 1939 cuando el jefe del Estado reglamente sus funciones, en vigor hasta 1977. Su labor estará centrada en las mujeres y los niños (en los últimos años también se encargaría de llevar sus planes de acción pedagógica a los hombres), fundamentalmente mediante actividades extraescolares aunque, al igual que pasaría con el Frente de Juventudes, muchas de sus actividades se realizaron dentro de las escuelas en horario lectivo.

Desde sus comienzos, ambas organizaciones jugaron un papel determinante en el terreno educativo-musical, empresa que quedaría consolidada con la aprobación de la Ley de Educación de 1945 que, en su Capítulo v, art. 45, las capacitaría para desarrollar las actividades oportunas para acercar la música a los escolares, tanto a nivel formal como mediante la programación y realización de actividades extraescolares, aunque sus puntos de vista pedagógicos y metodológicos serían diametralmente opuestos; mientras que el Frente de Juventudes apostó por un estilo premilitar basado en el canto de himnos y marchas destinados a ensalzar la Patria y el Movimiento, la Sección Femenina se preocupó por ofrecer una formación musical completa como parte importante del desarrollo cultural básico de mujeres y niños (López García, 20I5).

En la siguiente tabla se exponen las peculiaridades educativo-musicales más significativas de cada una de estas instituciones, de las que se desprende el gran contraste entre ambas y la gran disparidad en sus modelos pedagógicos aunque, en ambos casos, en consonancia con las líneas de actuación marcadas por el Movimiento Nacional.

Tabla i. Conceptos pedagógico-musicales del Frente de Juventudes y de la Sección Femenina

\begin{tabular}{|c|c|}
\hline udes & nina \\
\hline $\begin{array}{l}\text { - Fórmula memorística de aprendizaje imita- } \\
\text { tivo. } \\
\text { - Importancia de los mensajes literales sobre } \\
\text { los musicales. } \\
\text { - Utilización de la música como conforma- } \\
\text { dora de estados de ánimo de masas. } \\
\text { - Potenciación del canto colectivo monódico } \\
\text { a viva voz. } \\
\text { - La canción ocupa un lugar destacado en la } \\
\text { formación de los jóvenes. Sus tres elemen- } \\
\text { tos fundamentales son: la música (el ritmo, } \\
\text { no la melodía), la letra y el mensaje. } \\
\text { - A través de su revista Mástil ofrece indica- } \\
\text { ciones e instrucciones para enseñar cancio- } \\
\text { nes, himnos y marchas. } \\
\text { - Especialmente dedicado al ámbito extraes- } \\
\text { colar y no formal: campamentos, desfiles, } \\
\text { excursiones... } \\
\text { - Preponderancia de himnos y marchas en su } \\
\text { repertorio. }\end{array}$ & $\begin{array}{l}\text { - La música se utiliza como medio ideal para } \\
\text { la transmisión del tradicionalismo y la reli- } \\
\text { giosidad. } \\
\text { - El estudio de la música es un medio para la } \\
\text { mejora social futura. } \\
\text { - Gran importancia de la transmisión de la } \\
\text { cultura musical mediante la selección, difu- } \\
\text { sión y representación. } \\
\text { - A través de su revista Consigna ofrece in- } \\
\text { dicaciones metodológicas para la enseñanza } \\
\text { y aprendizaje de canciones, divulga biogra- } \\
\text { fías de los principales compositores clásicos } \\
\text { y realiza una tarea valiosísima de recupera- } \\
\text { ción y conservación del folclore nacional. } \\
\text { - A partir de los años so se ve una intención } \\
\text { más culturizadora introduciendo lecciones } \\
\text { de historia de la música, realización de con- } \\
\text { ferencias y audiciones, programación de } \\
\text { conciertos para escolares... } \\
\text { - Apertura del hecho musical a toda la socie- } \\
\text { dad. }\end{array}$ \\
\hline
\end{tabular}


EL PATRONATO DE MISIONES PEDAGÓGICAS, EL FRENTE DE JUVENTUDES

Y LA SECCIÓN FEMENINA: INSTITUCIONES CLAVE EN LA HISTORIA...

NARCISO JOSÉ LÓPEZ GARCÍA Y MARÍA DEL VALLE DE MOYA MARTÍNEZ

\begin{tabular}{|c|c|}
\hline Frente de Juventudes & Sección Femenina \\
\hline $\begin{array}{l}\text { - Los principios de calidad interpretativa } \\
\text { quedan en un segundo plano. } \\
\text { - Se valora más el ritmo que la melodía. } \\
\text { - Se busca un aprovechamiento de las faci- } \\
\text { lidades innatas y la imitación más que un } \\
\text { proceso formativo o educativo. } \\
\text { - Se busca fomentar la cohesión emocional } \\
\text { del grupo mediante el canto colectivo. } \\
\text { - El folclore se convierte en elemento de ex- } \\
\text { presión sentimental. } \\
\text { - Se fomentan las bandas militares, especial- } \\
\text { mente de tambores y cornetas. }\end{array}$ & $\begin{array}{l}\text { - Se programan cursos nacionales e inter- } \\
\text { nacionales de especialización musical para } \\
\text { profesores. } \\
\text { - Educación musical de la población escolar } \\
\text { abierta a todos, independientemente de cua- } \\
\text { lidades innatas, basado en la expresión de } \\
\text { emociones y el desarrollo de la creatividad. }\end{array}$ \\
\hline
\end{tabular}

Fuente: Elaboración propia basada en los datos ofrecidos por CASTAÑón (2009).

Aunque su papel a nivel escolar fue prácticamente nulo, merece una breve mención la Obra Sindical de Educación y Descanso, institución formada por trabajadores que colaboró en la recopilación, estudio y divulgación del folclore musical español. Esta nació de la necesidad de atender la demanda educativa y formativa de los trabajadores en sus horas libres y recreos. Surgió en 1939 con el objetivo de proporcionar momentos de ocio (López Gallegos, 2004). Para llevar a cabo esta labor, la Obra Social programó conferencias, creó bibliotecas y organizó grupos artísticos en los que se impartían clases de solfeo y canto y desde los que se impulsaron y promovieron corales y grupos de coros y danzas que se encargarían de dar a conocer nuestro folclore tanto dentro como fuera de nuestras fronteras.

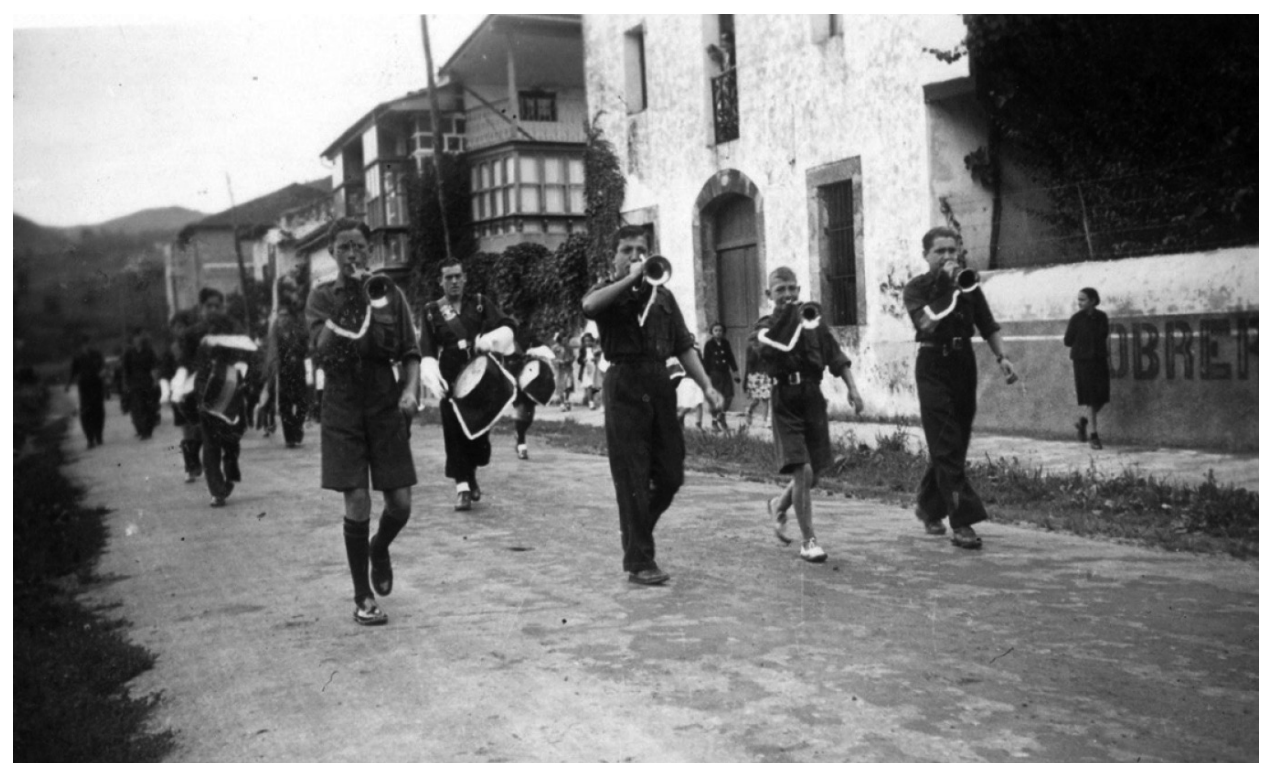

Figura 3. Banda de tambores y cornetas del Frente de Juventudes (I945) (en http://ampuerobrera.blogspot.com.es/2013_05_oI_archive.html). 
EL PATRONATO DE MISIONES PEDAGÓGICAS, EL FRENTE DE JUVENTUDES Y LA SECCIÓN FEMENINA: INSTITUCIONES CLAVE EN LA HISTORIA... NARCISO JOSÉ LÓPEZ GARCÍA Y MARÍA DEL VALLE DE MOYA MARTÍNEZ

\section{Actividades relacionadas con la Educación Musical programadas desde la Sección Femenina}

La Sección Femenina se encargó de que gran parte de nuestro folclore haya llegado intacto hasta nosotros (Alonso, 200I) a través de diferentes libros y publicaciones como Cultura Musical, Mil canciones españolas, Canciones populares para escolares, Canciones y danzas de España o Educación Musical Preescolar, entre otros, así como un abundante número de canciones litúrgicas y populares y lecciones de teoría de la música que se publicaron mensualmente en la revista Consigna entre I940 y 1977.

Por otro lado, esta institución realizó treinta y siete consejos nacionales, muchos de ellos de gran relevancia en el desarrollo y auge de la música y de la educación musical, creó grupos de Coros y Danzas; llevó a cabo conciertos y concursos de audiciones musicales y de villancicos; y colaboró en la inclusión de la asignatura de Música, como materia independiente, dentro del plan de estudios del Bachillerato Unificado Polivalente (Alonso, 200I). Además, Allué (20I6) nos recuerda que una de las iniciativas más populares de la Sección Femenina fueron los campamentos y albergues de verano, en los que la enseñanza de canciones populares y, posteriormente, su memorización, recopilación y fijación escrita por parte de las niñas participantes llegó a convertirse en una de las actividades fundamentales de estas jornadas.

Otra de las actividades desarrolladas desde sus orígenes fueron los cursos de música para instructoras y maestras que se convirtieron en una de las actividades principales de la organización y que, desde nuestro punto de vista, merecen una especial atención.

\section{Los cursos de música impartidos por la Sección Femenina}

Estos cursos estaban pensados, principalmente, para formar a las personas (instructoras de la Sección Femenina y profesorado de música) que tenían a su cargo la enseñanza de la música en colegios, institutos o escuelas hogar. Los programas de estos cursos eran revisados y actualizados con frecuencia para adaptarlos a los planes de estudios que se iban publicando (Alonso, 2002).

Existían cinco modalidades diferentes con las que se intentaba atender a las necesidades y posibilidades de los profesionales:

- Cursos Nacionales de Música y Danza: en régimen de internado y con una duración de dos años, estaban diseñados, fundamentalmente, para la formación de instructoras. Para poder acceder a éstos era necesario tener el título de Música del Conservatorio y el Bachiller Elemental o una formación equivalente. Se celebraban en Barcelona.

- Cursos Provinciales de Música y Danza: a estos cursos solían asistir aquellas personas que, estando capacitadas, no podían permanecer dos años en Barcelona. La duración y la carga lectiva dependía del número de alumnos y del programa de materias que se establecía. Iban dirigidos a la preparación de maestros de coros.

- Cursillos Especiales: para profesores de música (con unos programas más completos y específicos) o para maestros y educadores en general. Se centraban en dar a conocer los nuevos sistemas de enseñanza de la música que iban surgiendo en el panorama educativo internacional. 
EL PATRONATO DE MISIONES PEDAGÓGICAS, EL FRENTE DE JUVENTUDES

Y LA SECCIÓN FEMENINA: INSTITUCIONES CLAVE EN LA HISTORIA...

NARCISO JOSÉ LÓPEZ GARCÍA Y MARÍA DEL VALLE DE MOYA MARTÍNEZ

- Cursos Especiales de Verano: celebrados en Santander. Ofrecían la posibilidad de formarse o de ampliar conocimientos en actividades tales como canto, audición musical, escucha activa, organización de conciertos, dirección de coros, enseñanza de la música y sistema Orff.

- Cursos de Renovación: específicos para la actualización de instructoras de la Sección Femenina. Se celebraban en Madrid.

Alonso (20or) no duda en afirmar que estos cursos, que no pretendían preparar grandes intérpretes, sino que se encargaban de capacitar a sus asistentes para impartir la Música dentro de los planes de formación de la Sección Femenina, dieron lugar a una titulación académica que, en muchos casos, facilitó una profesión para la mujer.

\section{Las Cátedras Ambulantes de la Sección Femenina}

Nacidas en 1946 y conocidas también como Cátedras Nacionales Motorizadas (Rebollo, 2005), se pueden definir como escuelas sobre ruedas encargadas de visitar los municipios menores de 5000 habitantes, con el fin de mejorar sus aspectos económicos, culturales, sociales y espirituales y de divulgar enseñanzas prácticas aplicadas al medio rural.

Comenzaron su andadura en 1946 y dependieron directamente del Departamento de Formación de la Sección Femenina. Solían permanecer entre 45 y 60 días en el pueblo o aldea al que se habían desplazado, dependiendo de las necesidades de sus habitantes y de la programación que llevaban prevista.

Rebollo (2005) nos explica que su aspecto era el de una pequeña caravana motorizada formada por un grupo de entre 5 y io personas (sin contar a los conductores) y 4 o 5 camiones-remolque cuya composición básica era:

- Un camión vivienda con cocina, cuarto de estar, aseo y dormitorio.

- Un camión sala de estar y exposición.

- Un camión clínica con rayos X, mesa de reconocimiento y laboratorio.

- Dos camiones convertibles en aulas, con capacidad para unas 50 personas.

Ramos y Rabazas (2007) dividen las actividades y enseñanzas que se impartían en grupos diferenciados según el sexo y la edad. En cuanto a la edad, existían dos tipos de programas: uno para las mujeres mayores, cuya formación se centraba en las enseñanzas de religión, formación político-social, educación física, canciones y danzas, puericultura e higiene, cultura general, industrias rurales (cunicultura, avicultura, chacinería, conservería, horticultura, jardinería...) y hogar (labores, cocina, corte y confección, decoración, economía doméstica...); y otro para las jóvenes, cuya formación estaba centrada en la educación física, música, formación cívico-política y social y otras enseñanzas y actividades complementarias. Los hombres podían asistir a las clases de artesanía, industrias rurales y cultura general que se llevaban a cabo al atardecer, junto con los niños y ancianos con los que se realizaban actividades de ocio y entretenimiento de todo tipo (López García, 20I5).

Con respecto a las actividades musicales, Pérez Zalduondo (20II) nos recuerda que estas Cátedras Ambulantes se centraron, casi en exclusiva, en promocionar la música de tradición oral, convirtiendo al folclore musical en principal protagonista del proceso educativo-musical llevado a cabo por la Sección Femenina. 


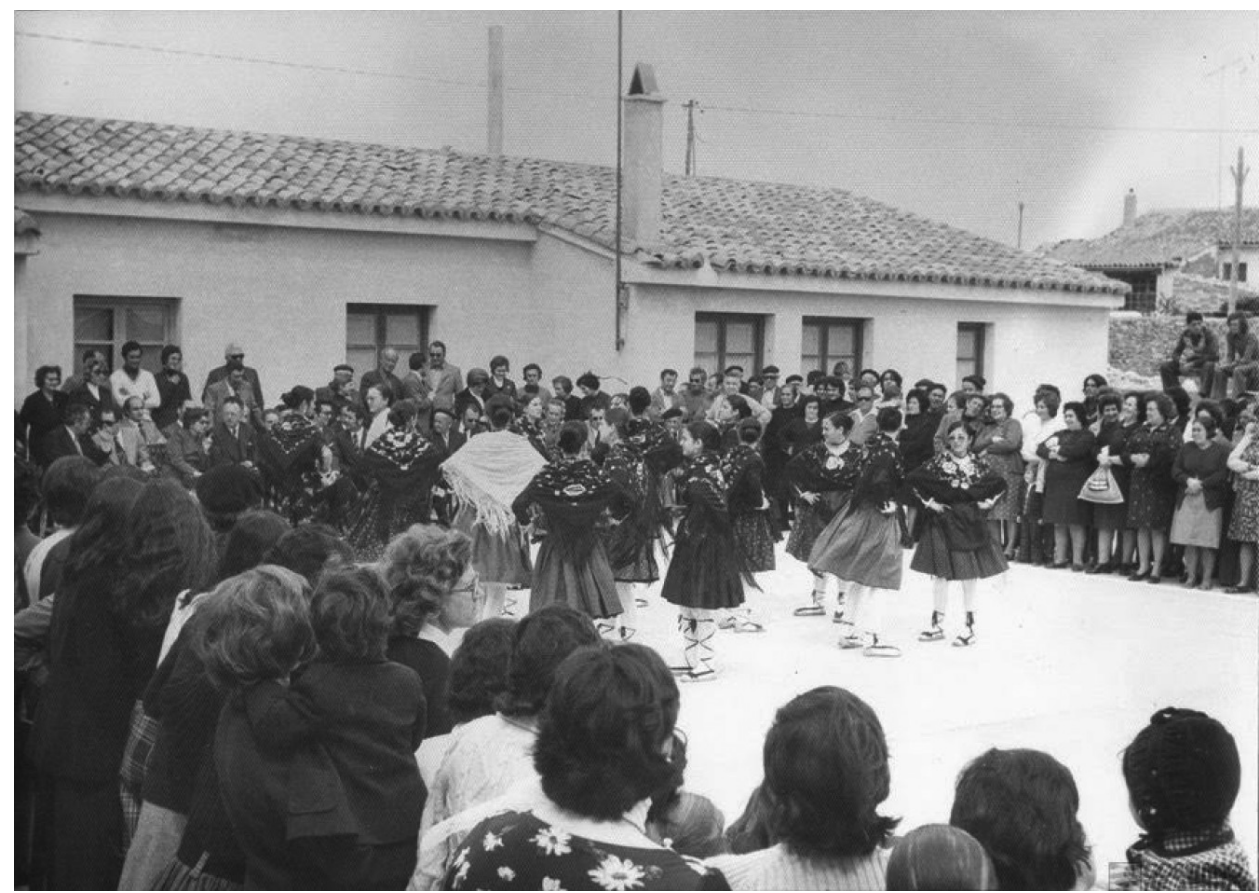

FIgURA 4. Grupo de chicas realizando actividades de baile y danza programadas por las Cátedras Ambulantes (1975) (en http://geneavinaceite.blogspot.com.es/p/blog-page_9390.html).

Mientras que la Cátedra permanecía en una localidad, las instructoras se encargaban, también, de recoger datos acerca del lugar: fechas de sus fiestas y romerías, canciones típicas de la zona, recetas de cocina, trajes regionales, bailes y danzas populares... Sin embargo, y como nos vuelve a recordar Rebollo (2005), su principal misión fue la de educar a las mujeres en la doctrina nacional-sindicalista y católica para que fuesen de utilidad en la familia, en el municipio y en el sindicato. Además, el éxito o el fracaso de estas Cátedras radicaba en lo bien o mal adoctrinados que quedaban los ciudadanos, una vez terminada la misión, para servir debidamente a la Patria y a la sociedad.

Estas Cátedras Ambulantes dieron lugar a las Cátedras Fijas, o Cátedras José Antonio, con el objetivo de aplicar los mismos métodos de las Ambulantes pero en las zonas periféricas y barrios más deprimidos de las grandes ciudades, en las que la emigración del campo a la ciudad había ocasionado grandes desajustes socioeconómicos y numerosas bolsas de pobreza material y espiritual. Las Ambulantes se extendieron, especialmente, entre 1955 y 1977, año en que dejaron de realizar su labor, llegando a todas las provincias españolas y a alguna provincia africana. En los últimos años, el número de cátedras ascendía a 80 y contaban con cerca de 400 profesoras (Pérez Moreno, 2013). Durante todo ese tiempo, tuvieron siempre presente la idea de contribuir a la alfabetización de los pueblos (Ramos y Rabazas, 2007). 
EL PATRONATO DE MISIONES PEDAGÓGICAS, EL FRENTE DE JUVENTUDES

Y LA SECCIÓN FEMENINA: INSTITUCIONES CLAVE EN LA HISTORIA...

NARCISO JOSÉ LÓPEZ GARCÍA Y MARÍA DEL VALLE DE MOYA MARTÍNEZ

TABla 2. Similitudes y diferencias fundamentales en las actuaciones del Patronato de Misiones Pedagógicas y de las Cátedras Ambulantes.

\begin{tabular}{|l|l|}
\hline \multicolumn{1}{|c|}{ Patronato de Misiones Pedagógicas } & \multicolumn{1}{|c|}{ Cimilitudes fundamentales } \\
\hline \multicolumn{1}{|c|}{ Cátedas Ambulantes } \\
\hline $\begin{array}{l}\text { - Ambas, salvando las distancias político-temporales, pretenden llevar la cultura a los pue- } \\
\text { blos más pequeños, alejados y peor comunicados. }\end{array}$ \\
- Preocupación por la población rural y por su educación básica. \\
- El interés por divulgar, «repopularizar» y recopilar el folclore musical se convierte en uno \\
de sus puntos fuertes. \\
- Fuerte vínculo de la cultura artística con la ideología. \\
\hline \multicolumn{2}{|c|}{ Diferencias fundamentales } \\
\hline $\begin{array}{l}\text { Apuesta por trasladar la cultura mediante el } \\
\text { goce de la misma (poesía, música, teatro...), } \\
\text { reconociendo la propia cultura de los pueblos } \\
\text { visitados. }\end{array}$ & $\begin{array}{l}\text { Sentido más práctico (corte y confección, ar- } \\
\text { tesanía, cocina...). A su vez, se encargaban de } \\
\text { recopilar las tradiciones propias de las zonas a } \\
\text { las que se desplazaban. }\end{array}$ \\
\hline $\begin{array}{l}\text { Actuaciones breves. } \\
\text { Formado por voluntarios (intelectuales de la } \\
\text { época y estudiantes normalistas y universi- } \\
\text { tarios). }\end{array}$ & $\begin{array}{l}\text { Personal con formación específica y dedica- } \\
\text { tinuidad. } \\
\text { ción exclusiva. }\end{array}$ \\
\hline $\begin{array}{l}\text { Es un claro reflejo de los nuevos aires políti- } \\
\text { cos, sociales y culturales del momento. }\end{array}$ & $\begin{array}{l}\text { Modelo que surge con un régimen político } \\
\text { consolidado. }\end{array}$ \\
\hline
\end{tabular}

Fuente: Elaboración propia basada en los datos ofrecidos por SÁNCHEZ Llamas (1994).

\section{Conclusiones}

La historia educativa del siglo xx español está jalonada por diversas tentativas para adjudicar a la enseñanza musical un puesto y un reconocimiento propios en las diversas legislaciones e iniciativas musicales y culturales que tuvieron lugar a lo largo de esta centuria, culminando con la implantación de la Ley Orgánica de Ordenación General del Sistema Educativo (LOGSE), en 1990, y convirtiendo a esta época en el período más fructífero en pro de una educación musical básica, reglada, obligatoria y al alcance de todos.

A pesar de las múltiples dificultades, fundamentalmente económicas y de escasez de recursos humanos, al no disponer de una plantilla de profesores especializados, destellan con brillo propio dos iniciativas de diferente sesgo político en lo ideológico, pero con la misma finalidad: acercar la música a la mayor cantidad posible de población, en especial, a los grupos más desfavorecidos. La primera, el Patronato de Misiones Pedagógicas, tuvo una corta vida, truncada con el fratricidio civil; la segunda iniciativa, llevada a cabo por el Frente de Juventudes y por la Sección Femenina, más longeva en el tiempo, estuvo marcada por cierta utilización de la música como «arma del Movimiento para adoctrinar a las masas», pero no sería objetivo ni riguroso menospreciar el papel de ambas instituciones como difusoras de la música y la cultura musical nacionales.

Desde esta perspectiva, es de justicia reconocer que los dos grandes proyectos de musicalización nacional recogidos en el presente artículo, aunque edificados sobre 
diferentes modelos políticos y, como consecuencia directa de ello, con postulados educativos contrastantes, confluyeron en una idea común: acercar la música y la cultura musical a todos los rincones de la geografía española, intentando disminuir, en lo posible, la enorme separación existente entre el mundo rural y el mundo urbano del siglo xx, no sólo en lo económico, sino también en lo intelectual y cultural.

La falta de currículos oficiales que, a lo largo de la historia más reciente de la educación en España, apoyaran la enseñanza de la música en las escuelas, encontró una compensación en las actividades musicales llevadas a cabo por estas tres instituciones, especialmente por las Misiones Pedagógicas y las Cátedras Ambulantes, que se encargaron de desarrollar una labor fundamental de recogida y difusión de canciones populares y de folclore musical español y de formación de docentes en estrategias y métodos musicales que, posteriormente, aplicarían en sus lugares de trabajo.

Este camino, arduo y difícil de recorrer, nos ha llevado al momento actual, donde la Música es una asignatura de pleno derecho en los currículos oficiales, con profesionales especializados para su impartición en la etapas de Educación Primaria y Secundaria y con muchos más recursos, a pesar de las carencias que siguen existiendo. Y aun así, la musicalización social española y la valoración general de la población hacia la Música y sus diversas manifestaciones no parecen haber alcanzado cotas espectaculares, siendo muchas las lagunas existentes, con gran trabajo pendiente por parte de instituciones educativas, centros, profesores y colectivos sociales. Quizás falte la ilusión que demostraron los componentes de las citadas instituciones para llevar a cabo esta labor artística y educativa que, en estos momentos, no parece estar a la altura de nuestros vecinos europeos.

\section{Bibliografía}

Allué, C. (2016) Canciones populares para niñas de la Sección Femenina de la Falange. Estudio de un cuaderno manuscrito de 1953. Huarte de San Juan. Filología y Didáctica de la Lengua, I6, 8I-IIo. Recuperado el I2 de enero de 20I7, de http://academica-e.unavarra.es/bitstream/ handle/2454/22720/HSJ_Filolog\% $3 \%$ ADa_16_2016_Canciones.pdf?sequence=I.

Alonso, J. A. (200I) La Sección Femenina: legado musical. El Guiniguada, IO, II-24. Recuperado el I2 de marzo de 20I4, de http://acceda.ulpgc.es/bitstream/I0553/54I9/I/O235347_ O200I_Oooi.pdf.

Alonso, J. A. (2002) Cursos de formación musical para instructoras de la Sección Femenina y para el profesorado en general. El Guiniguada, II, II-2I. Recuperado el I2 de marzo de 20I4, de http://acceda.ulpgc.es/bitstream/I0553/5454/I/0235347_02002_000I.pdf.

BARdin, L. (2002) Análisis de contenido. Tres Cantos (Madrid): Akal.

Canes, F. (1993) Las misiones pedagógicas: educación y tiempo libre en la Segunda República. Revista Complutense de Educación, I (4), I47-I68. Recuperado el 5 de diciembre de 20I3, de http://revistas.ucm.es/index.php/RCED/article/view/RCED9393120I47A.

Cañabate, J. A. (2003-2004) La pugna entre la Iglesia Católica y el Frente de Juventudes en el ámbito educativo. Referencias internacionales, antecedentes y trayectoria general durante el primer franquismo. Historia de la Educación, 22-23, I05-I2I.

Castañón, M. R. (2009) El profesorado de educación musical durante el franquismo. Revista Electrónica Interuniversitaria de Formación del Profesorado, I2 (4), 97-107. Recuperado el 21 de febrero de 20I4, de https://dialnet.unirioja.es/servlet/articulo?codigo $=3086748$.

De Puelles, M. (I99I) El sistema educativo republicano: un proyecto frustrado. Historia Contemporánea, 6, I59-I7I. 
EL PATRONATO DE MISIONES PEDAGÓGICAS, EL FRENTE DE JUVENTUDES

Y LA SECCIÓN FEMENINA: INSTITUCIONES CLAVE EN LA HISTORIA...

NARCISO JOSÉ LÓPEZ GARCÍA Y MARÍA DEL VALLE DE MOYA MARTÍNEZ

Díaz Gómez, M. y Giráldez, A. (coords.) (2007) Aportaciones teóricas y metodológicas a la educación musical. Una selección de autores relevantes. Barcelona: Graó.

Dulzaides, M. E. y Molina, A. M. (2004) Análisis documental y de información: dos componentes de un mismo proceso. ACIMED, 2. http://eprints.rclis.org/50I3/r/analisis.pdf.

Hemsy de Gainza, V. (2003) La educación musical entre dos siglos: del modelo metodológico a los nuevos paradigmas. Documento de trabajo n. ${ }^{\circ}$ Io. Argentina: Escuela de Educación, Universidad de San Andrés. Serie Documentos de Trabajo.

LONGUEIRA, S. (2OII) Educación musical: un problema emergente de intervención educativa. Indicadores pedagógicos para el desarrollo de competencias en educación musical. Tesis doctoral no publicada. Universidad de Santiago de Compostela. Santiago de Compostela.

López Casanova, M. B. (2002a) La música en el magisterio de las escuelas normales y su proyección en la primera escuela desde 1837 a 1930. Música y Educación. Revista Trimestral de Pedagogía Musical, 49, 29-44.

López Casanova, M. B. (2002b) La política educativo-musical en España durante la Segunda República. Música y Educación. Revista Trimestral de Pedagogía Musical, 50, I5-25.

López Gallegos, M. S. (2004) El control del ocio en Italia y España: de la Ópera Nazionale Dopolavoro a la Obra Sindical de Educación y Descanso. Investigaciones Históricas: Época Moderna y Contemporánea, 24, 215-236. Recuperado el 7 de septiembre de 20I5, de https:// dialnet.unirioja.es/servlet/articulo?codigo $=902304$.

López García, N. J. (20I5) Necesidades profesionales del profesorado especialista de música de los centros de primaria de Castilla-La Mancha. Tesis doctoral no publicada. Universidad de Málaga. Málaga.

Lorenzo QuiLEs, O. (2003) Educación musical reglada en la enseñanza general española: 19392002. Tavira: Revista de Ciencias de la Educación, 19, 13-34.

Manrique, J. C.; López, V. M.; Torrego, L. M. y Mongas, R. (2008) La labor formativa desarrollada por la Sección Femenina de la Falange en la preparación de sus mandos e instructoras durante el período franquista. Historia de la Educación, 27, 347-365. Recuperado el 24 de mayo de 20I4, de https://dialnet.unirioja.es/servlet/articulo?codigo=30I0I65.

Martín, M. (2002) Las misiones pedagógicas en Salamanca (1931-1936). Aula, I4, I55-178. Recuperado el 2 de septiembre de 2014 , de http://campus.usal.es/ revistas_trabajo/index. $\mathrm{php} / 0214-3402 /$ article/viewFile/ı308/1379.

Martínez del Fresno, B. (20I0) La Sección Femenina de la Falange y sus relaciones con los países amigos: música, danza y política exterior durante la Guerra y el primer franquismo (1937-1943). En G. Pérez y M. I. Cabrera (coords.) Cruces de caminos: intercambios musicales y artísticos en la Europa de la primera mitad del siglo XX (pp. 357-406). Granada: Editorial Universidad de Granada.

Morales, A. (2008) La educación musical en primaria durante la LOGSE en la comunidad de Madrid: análisis y evaluación. Tesis doctoral no publicada. Universidad Autónoma de Madrid. Madrid.

OcañA, A. (2006) Identidad y ciclos de desarrollo profesional de los maestros y maestras de educación musical. Granada: Universidad de Granada. Facultad de Ciencias de la Educación. Departamento de Métodos de Investigación y Diagnóstico Educativo.

Oriol, N. (2005) La música en las enseñanzas de régimen general en España y su evolución en el siglo xx y comienzos del xxI. LEEME. Revista de la Lista Electrónica Europea de Música en la Educación, I6. Recuperado el 3 de abril de 20I4, de https://dialnet.unirioja.es/servlet/ articulo?codigo $=\mathrm{I} 3728 \mathrm{I} 2$.

Patronato de Misiones Pedagógicas (1934) Memorias. Septiembre de ig3i-Diciembre de 1933. Madrid: S. Aguirre, Impresor.

Patronato de Misiones Pedagógicas (1935) Memoria de la misión pedagógico-social en Sanabria (Zamora). Resumen de trabajos realizados en el año 1934. Madrid: S. Aguirre, Impresor. 
Pérez Moreno, H. M. (20I3) Educación y asistencia social de una escuela errante durante el franquismo en España. RES. Revista de Educación Social, i7. Recuperado el i6 de enero de 20I5, de http://www.eduso.net/res/pdf/r7/cateam_res_I7.pdf.

Pérez Prieto, M. (200I) La organización de la educación musical en España desde i970: estudio a partir de los textos legales de ámbito estatal. Aula, I3, I9I-213. Recuperado el I4 de agosto de 20I4, de http://campus.usal.es/ revistas_trabajo/index.php/o2I4-3402/article/ viewFile/3610/3628.

Pérez Zalduondo, G. (2006) Ideología y política en las instituciones musicales españolas durante la segunda república y primer franquismo. Quintana: revista de estudios do Departamento de Historia da Arte, 5 (5), I45-156. Recuperado el io de enero de 2015, de https:// dialnet.unirioja.es/servlet/articulo?codigo $=2655910$.

Pérez Zalduondo, G. (20II) Música, censura y falange: el control de la actividad musical desde la Vicesecretaría de Educación Popular. Arbor. Ciencia, Pensamiento y Cultura, 751 (I87), 875-886. Recuperado el II de enero de 20I5, de http://arbor.revistas.csic.es/index.php/ arbor/article/view/1357/1366.

Pliego, V. (2006) El servicio de música: Eduardo Martínez Torner y Pablo de Andrés Cobos. En Sociedad Estatal de Conmemoraciones Culturales y Residencia de Estudian-

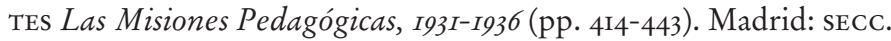

Ramos, S. y Rabazas, T. (2007) Mujeres e instrucción rural en el desarrollismo español. Historia de la Educación, 26, 22I-256.

Rebollo, M. P. (2005) Viaje al centro de ninguna parte: historia de las cátedras ambulantes. En A. SAbio (coord.) Las escalas del pasado: IV Congreso de Historia Local de Aragón (pp. 28I-288). Barbastro: Instituto de Estudios Altoaragoneses. UNED. Recuperado el 9 de octubre de 20I4, de https://dialnet.unirioja.es/servlet/articulo?codigo=I2I5945.

Reyes, M. L. (2005) La música en educación primaria. Una perspectiva desde el Maestro especialista. Granada: Universidad de Granada. Facultad de Ciencias de la Educación. Departamento de Didáctica de la Expresión Musical, Plástica y Corporal.

Romero, J. L. (20II) La educación en España: análisis, evolución y propuestas de mejora. Innovación y Experiencias Educativas, 42. Recuperado el I2 de marzo de 20I4, de http://www. csi-csif.es/andalucia/modules/mod_ense/revista/pdf/Numero_42/JOSE \% 20LUIS\% 20 ROMERO\% 20LACAL_I.pdf.

Romero Carmona, J. B. (2005) La música en la escuela y su tratamiento histórico. Música y Educación. Revista Trimestral de Pedagogía Musical, 62, 43-58.

Romero Carmona, J. B. (2009) Diseño, aplicación y evaluación de un material didáctico para optimizar la enseñanza musical en el tercer ciclo de la educación primaria. Huelva: Universidad de Huelva. Facultad de Ciencias de la Educación. Departamento de Educación.

SÁnchez Blanco, L. (20I2) La educación femenina en el sistema educativo español (1857-2007). El Futuro del Pasado, 3, 255-28I. Recuperado el 9 de junio de 20I4, de https://dialnet.unirioja. es/servlet/articulo?codigo $=394 \mathrm{I} 222$.

Sánchez Llamas, F. J. (1994) Dos visiones de educación popular. El Patronato de Misiones Pedagógicas y las Cátedras Ambulantes. Isla de Arriarán: Revista Cultural y Científica, 4, I29-I40. Recuperado el 7 de noviembre de 20I4, de https://dialnet.unirioja.es/servlet/articulo? codigo $=2709450$.

SECC (2007) Las Misiones Pedagógicas. I93I-1936. Madrid: Fundación Giner de los Ríos. Recuperado el I4 julio de 20I4, de http://www.residencia.csic.es/misiones/img/sedes/dossier_ prensa.pdf.

TAPIA, G. (dir.) (2006) Las Misiones Pedagógicas [Dvd]. España: SEcc-TVe. Acacia Films-Malvarrosa Media. 